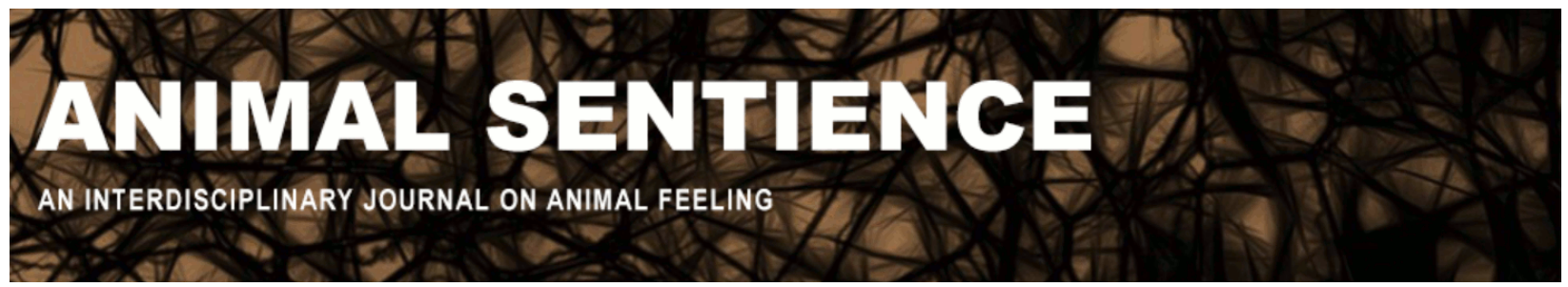

Vonk, Jennifer (2018) Researchers, not dogs, lack control in an experiment on jealousy. Animal Sentience 22(2)

DOI: $10.51291 / 2377-7478.1326$

Date of submission: 2018-05-15

Date of acceptance: 2018-05-17

(c) (†)

This article has appeared in the journal Animal

Sentience, a peer-reviewed journal on animal

cognition and feeling. It has been made open access,

free for all, by WellBeing International and deposited

in the WBI Studies Repository. For more information,

please contact

wbisr-info@wellbeingintl.org.

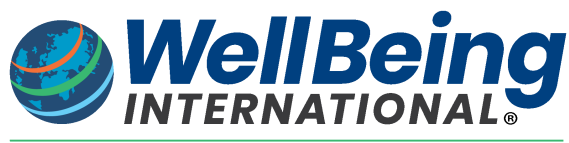

SOLUTIONS FOR PEOPLE, ANIMALS AND ENVIRONMENT 


\title{
Researchers, not dogs, lack control in an experiment on jealousy
}

\author{
Commentary on Cook et al. on Dog Jealousy
}

\author{
Jennifer Vonk \\ Psychology Department \\ Oakland University
}

\begin{abstract}
Cook and colleagues (2018) have developed a clever method to measure fMRI in awake dogs in response to a number of interesting stimuli. As a result, they are able to determine neural correlates of observable behavior. They report that dogs may experience something akin to jealousy because they show greater amygdala activation in response to food being given to a fake dog versus food being placed in a bucket. However, several critical controls are missing which prevent the authors from being able to speak of jealousy.
\end{abstract}

Jennifer Vonk is a professor of Psychology at Oakland University. She studies various aspects of cognition in a wide range of species. She is also interested in assessing animal welfare in captive settings. Jennifervonk.com

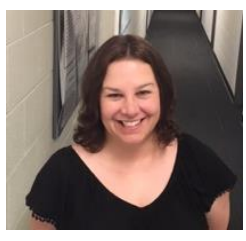

"Dogs are our link to paradise. They don't know evil or jealousy or discontent." Milan Kundera

The above quote from Kundera exemplifies the most conservative assessment of dogs' capacity to experience emotion. On the other end of the spectrum, people routinely attribute complex emotions to their pets. Recently developed methodology for measuring $\mathrm{fMRI}$ in awake canines has been a game changer in accessing brain correlates of cognitive and behavioral processes previously inaccessible to researchers. One longstanding question of interest to comparative psychologists and the public alike is whether other species experience emotions similar to those experienced by humans. There is little doubt that animals experience fear and anger - two adaptive emotions that facilitate appropriate protective responses in the presence of threatening stimuli. Animals' experience of other emotions, however, is less evident. Do they experience happiness and sadness? Animal correlates of even more complex emotions, such as shame, disgust, pride, and jealousy may be even more difficult to ascertain. Cook and colleagues (2018) have just published findings that suggest that dogs may experience jealousy when human caretakers deliver food to other dogs.

Although the authors are to be commended for the methodological advances in studying dogs' emotional experiences, the current experiment cannot distinguish between jealousy and other internal states. The comparison of responses to a fake dog versus a familiar neutral object are not valid. First, a fake dog is likely to be an unfamiliar and strange object. It may well be puzzling that it looks like a dog and yet does not smell, sound, or move like a dog. Although the researchers took care to rub the fake dog with the scent of another dog, it is unlikely that it emitted an odor commensurate with a real dog. In addition, the fake dog did not move, even 
when offered food, which would certainly be anomalous to observe. The subjects did not appear to be familiarized with the fake dog before being tested in the scanner. When presented with such an unfamiliar object, dogs are likely to be distressed and to respond as if in the presence of a threat. The neurological response to threat or confusion may be indistinguishable from that of jealousy. This experiment requires control conditions where fake dogs are present but not receiving attention/affection/food from caregivers, or perhaps are receiving attention from a stranger or disliked individual. Such controls were also lacking from a previous study that claimed to find evidence of jealousy in dogs when human owners interacted with a stuffed dog (Harris \& Prouvost, 2014).

In addition, dogs may perceive the food that goes into a bucket as still being available, whereas food that disappears into a fake dog may be perceived as no longer available. Thus, the dogs may be reacting to the likelihood of being able to access the food rather than out of jealousy. The authors acknowledge that they cannot rule out that dogs may show the same activation any time a perceived conspecific is present. Although they argue that it would be difficult to control the behavior of a real conspecific in the testing situation, they could present owners responding to another human, especially a child, which might also evoke feelings of jealousy. They could also present the fake dog in a context where it was not being "fed" or receiving attention from humans.

In Figure 2A, it appears that there are three groups of dogs in the moderate-sized sample; seven dogs with low dog-directed aggression scores, four dogs with intermediate scores, and two dogs with relatively higher scores. In each of these groups, dogs were quite variable in terms of their amygdala activation. The data appear to violate the assumption of homoscedasticity. That is, the data points are not distributed evenly across the variable of owner-reported dog-directed aggression. Instead, more than half of the data points are at the low end, with owners essentially reporting no aggression for these dogs. Thus, I am also skeptical about the reported relationship between dog-directed aggression scores and amygdala activation.

At a conceptual level, it is likely that being upset over losing a physical resource to another evokes a different emotional response, even in humans, compared to the kind of upset one experiences when one loses the attention or affection of another with whom one has a strong emotional bond. Is it still jealousy when one is upset by the loss of a valuable resource? It is unclear whether the neurological response measured here represents jealousy or arousal or irritation or surprise. Psychologists should take great care to define emotions operationally and use these definitions in a consistent and rigorous manner without using sensationalistic terminology to attract attention to what are otherwise provocative findings. Emotions are challenging enough to study without introducing confusion at the conceptual level.

\section{References}

Cook, P., Prichard, A., Spivak, M., \& Berns, G. S. (2018). Jealousy in dogs? Evidence from brain imaging. Animal Sentience 22(1).

Harris, C. R., \& Prouvost, C. (2014). Jealousy in dogs. PLoS ONE 9(7): e94597. 


\section{UQÀM/ISC Cognitive Science Summer School June 26 - July 6 2018, Montreal, Canada}

\section{The Other Minds Problem: Animal Sentience and Cognition}

Overview. Since Descartes, philosophers know there is no way to know for sure what - or whether - others feel (not even if they tell you). Science, however, is not about certainty but about probability and evidence. The 7.5 billion individual members of the human species can tell us what they are feeling. But there are 9 million other species on the planet (20 quintillion individuals), from elephants to jellyfish to mammals, with which humans share biological and cognitive ancestry, but not one other species can speak: Which of them can feel and what do they feel? Their human spokespersons - the comparative psychologists, ethologists, evolutionists, and cognitive neurobiologists who are the world's leading experts in "mind-reading" other species -- will provide a sweeping panorama of what it feels like to be an elephant, ape, whale, cow, pig, dog, chicken, mouse, fish, lizard, lobster, snail: This growing body of facts about nonhuman sentience has profound implications not only for our understanding of human cognition, but for our treatment of other sentient species.

Gregory Berns: Decoding the Dog's Mind with Awake

Neuroimaging

Gordon Burghardt: Probing the Umwelt of Reptiles

Jon Sakata: Audience Effects on Communication Signals

PANEL: Reptiles, Birds and Mammals

WORKSHOP: Kristin Andrews: The "Other" Problems: Mind,

Behavior, and Agency

Sarah Brosnan: How Do Primates Feel About Their Social

Partners?

Alexander Ophir: The Cognitive Ecology of Monogamy

Michael Hendricks: Integrating Action and Perception in a Small

Nervous System

PANEL: Primates, Voles and Worms

WORKSHOP: Jonathan Birch: Animal Sentience and the

Precautionary Principle

Malcolm MacIver: How Sentience Changed After Fish Invaded

Land 385 Million Years Ago

Sarah Woolley: Neural Mechanisms of Preference in Female

Songbird

Simon Reader: Animal Social Learning: Implications for

Understanding Others

PANEL: Sea to Land to Air

WORKSHOP: Steven M. Wise: Nonhuman Personhood

Tomoko Ohyama: Action Selection in a Small Brain (Drosophila

Maggot)

Mike Ryan: "Crazy Love": Nonlinearity and Irrationality in Mate

Choice

Louis Lefebvre: Animal Innovation: From Ecology to

Neurotransmitters

PANEL: Maggots, Frogs and Birds: Flexibility Evolving

SPECIAL EVENT: Mario Cyr: Polar Bears

Colin Chapman: Why Do We Want to Think People Are

Different?

Vladimir Pradosudov: Chickadee Spatial Cognition

Jonathan Balcombe: The Sentient World of Fishes

PANEL: Similarities and Differences

WORKSHOP (part 1): Gary Comstock: A Cow's Concept of Her

Future
WORKSHOP (part 2): Jean-Jacques Kona-Boun: Physical and

Mental Risks to Cattle and Horses in Rodeos

Joshua Plotnik: Thoughtful Trunks: Application of Elephant

Cognition for Elephant Conservation

Lori Marino: Who Are Dolphins?

PANEL: Mammals All, Great and Small

Larry Young: The Neurobiology of Social Bonding, Empathy and

Social Loss in Monogamous Voles

WORKSHOP: Lori Marino: The Inconvenient Truth About

Thinking Chickens

Andrew Adamatzky: Slime Mould: Cognition Through

Computation

Frantisek Baluska \& Stefano Mancuso: What a Plant Knows and

Perceives

Arthur Reber: A Novel Theory of the Origin of Mind:

Conversations With a Caterpillar and a Bacterium

PANEL: Microbes, Molds and Plants

WORKSHOP: Suzanne Held \& Michael Mendl: Pig Cognition and Why It Matters

James Simmons: What Is It Like To Be A Bat?

Debbie Kelly: Spatial Cognition in Food-Storing

Steve Phelps: Social Cognition Across Species

PANEL

WORKSHOP: To be announced

Lars Chittka: The Mind of the Bee

Reuven Dukas: Insect Emotions: Mechanisms and Evolutionary

Biology

Adam Shriver: Do Human Lesion Studies Tell Us the Cortex is

Required for Pain Experiences?

PANEL

WORKSHOP: Delcianna Winders: Nonhuman Animals in Sport and Entertainment

Carel ten Cate: Avian Capacity for Categorization and

Abstraction

Jennifer Mather: Do Squid Have a Sense of Self?

Steve Chang: Neurobiology of Monkeys Thinking About Other

Monkeys

PANEL

WORKSHOP: The Legal Status of Sentient Nonhuman Species 